\title{
Reflexos das políticas itinerantes \\ nas diretrizes curriculares nacionais \\ dos cursos de letras ${ }^{1}$
}

\section{Reflections of the Traveling Policies in the \\ Guidelines for Language and Literature \\ Programs}

Marco Antônio Margarido Costa*

Universidade Federal de Campina Grande (UFCG)

Campina Grande - Paraíba / Brasil

RESUMO: A expressão políticas itinerantes é criada por Lindblad e Popkewitz para designar conceitos que circulam em reformas educacionais e propostas curriculares, em nível internacional, como resultado de processos de globalização. Neste artigo, além de apresentarmos alguns desses conceitos em diversos países, discutimos como, no Brasil, as Diretrizes Curriculares Nacionais dos cursos de Letras trazem reflexos dessas políticas e quais suas implicaçōes para a formação de professores de línguas. De forma concomitante, buscar-se-á evidenciar que essas políticas itinerantes são ambivalentes e podem ser interpretadas como processos de desregulamentação e privatização de deveres decorrentes da modernidade líquida, conforme interpretação de Bauman (2001).

PALAVRAS-CHAVE: políticas itinerantes, diretrizes curriculares, pósmodernidade, ambivalência, globalização.

ABSTRACT: The expression traveling policies is coined by Lindblad and Popkewitz to refer to concepts that circulate internationally in educational reforms as a result of processes of globalization. The objective of this paper is to present some of these concepts in many different countries, analyze how, in Brazil, the National Guidelines for Language and Literature Programs are equally in agreement with these policies and what their implications for the language teacher education are. Meanwhile, it will be argued that these traveling policies are ambivalent and can be seen as processes of deregulation and privatization of tasks and duties due to times of liquid modernity. KEYWORDS: traveling policies, guidelines, postmodernity, ambivalence, globalization.

*marcanco@terra.com.br

${ }^{1}$ Agradecemos à professora Terezinha Alves Fernandes (UFPB) pelas contribuições apresentadas à primeira versão deste texto e pelo constante diálogo sobre questôes educacionais. 


\section{Introdução}

Bauman (1999) afirma que a modernidade foi um período marcado pela promessa da ordem do mundo, do habitat humano, do eu humano e da conexão entre os três, em que se acreditava na clareza e na transparência da vida humana. Um dos grandes embates da modernidade, então, para esse sociólogo, é a tentativa de sufocar a ambivalência presente no mundo, especialmente na linguagem. Desse modo, admite que a pós-modernidade é o momento de se aprender a viver com a ambivalência, a ambiguidade, a bifurcação de sentidos.

Uma das características da pós-modernidade é a desregulamentação e a privatização das tarefas e deveres modernizantes. O que costumava ser visto como tarefa coletiva ou atribuição do Estado, do governo, de uma instituição, passou a ser atribuição de cada indivíduo. Para Bauman (2001, p. 37), na pósmodernidade, "nós, humanos, nos encontramos por nossa própria conta". Esse autor entende por individualização o fato de "transformar a 'identidade' humana de um 'dado' em uma 'tarefa' e encarregar os atores da responsabilidade de realizar essa tarefa e das consequências (assim como dos efeitos colaterais) de sua realização" (p. 40). O despertar e a compreensão da responsabilidade individual estão entre as principais implicaçôes de tal mudança, conforme advoga.

As afirmações do sociólogo nos provocam a refletir sobre as implicações e decorrências dessa característica da pós-modernidade no campo educacional, notadamente na formação de professores de línguas. Sendo assim, buscamos, no presente artigo, discutir primeiramente como se dá tal delegação de deveres para o indivíduo, em reformas educacionais e propostas curriculares, em nível internacional, para, em seguida, debruçarmo-nos sobre esse movimento no contexto brasileiro.

\section{Reformas Curriculares: variações de um mesmo sentido?}

Lindblad e Popkewitz (2004b, p. vii) consideram que reestruturações educacionais assumiram grande importância nas últimas décadas. $\mathrm{Na}$ área da educação, as transformações estão relacionadas a aspectos como a descentralização, a desregulamentação, a mercantilização, entre outros, com o objetivo de mudar as relaçóes do Estado com a sociedade civil. A fim de indicarem essa mudança do papel do Estado, que transfere para outros órgãos (públicos ou privados) a organização e a administração de instituiçóes sociais, 
com base na teoria foucaultiana de governamentalidade, ${ }^{2}$ os autores adotam o termo governance (LINDBLAD; POPKEWITZ, 2004b, 2004c).

Segundo esses educadores, as transformações ocorrem também nos programas de cursos de formação de professores. Consequentemente, as propostas na área das políticas curriculares também apresentam orientaçóes a fim de incorporar mudanças culturais, sociais e econômicas que vêm com palavras de ordem, tais como "sociedade do conhecimento" 3 e "aprendiz ao longo da vida" ou "eterno aprendiz". Essas transformaçōes envolvem ainda o perfil do aluno sob responsabilidade da escola e suas relações com a comunidade, a nação e com processos globais.

Para esses autores, reforma educacional é um conceito de sentido mutante. Assim, na coletânea por eles organizada, pesquisadores apresentam reformas educacionais em diversos continentes e discorrem sobre como expressóes de caráter global assumem características locais. O objetivo dessa pesquisa, segundo seus autores, não é avaliar a aplicabilidade das mudanças, mas sim analisar como as regras e os padrôes estabelecidos são possíveis de serem pensados na forma pela qual se apresentam. Para esse exercício, o termo "system of reason" (POPKEWITZ, 1998) é mobilizado para designar os princípios de regras e padróes de pensamento que governam, normalizam e naturalizam ações. Entendemos que sistemas de razão (tradução nossa) são os mecanismos empregados para que um conceito seja expresso da maneira como é apresentado; os raciocínios formulados que tornam uma ideia, conceito, princípios naturalizados ou aceitos como verdades inquestionáveis.

Essas reformas trazem palavras de ordem com sentidos semelhantes em diferentes contextos e países e, portanto, são apresentadas como um fenômeno global. Na Inglaterra, por exemplo, expressōes como "justiça social" e "negócios", "individualismo competitivo", "membro de uma equipe" aparecem em reformas educacionais, assumindo um caráter de verdade, no qual não há controvérsias ou ambiguidades. Na França, noções de "integração social" e "nova solidariedade entre classes sociais" são apresentadas. Na Argentina e Taiwan, os termos recorrentes são "democratização" e "desregulamentação" que aparecem combinados com a expressão "responsabilidade pessoal". Em

\footnotetext{
${ }^{2}$ Foucault (2003) analisou como as táticas de reforma do Estado foram transportadas para a vida cotidiana por meio da arte de governar. Tais táticas de reforma englobam mudanças institucionais e a individualização de problemas sociais.

${ }^{3}$ A tradução desse e dos demais termos entre aspas, ao longo do artigo, é nossa.
} 
Portugal, os termos encontrados em mudanças educacionais são "educação ao longo da vida e treinamento", "sociedade do conhecimento" e "globalização". Enfim, essas são algumas palavras e expressōes encontradas quando questōes de mudanças educacionais estão em andamento. Os autores da coletânea trazem, desse modo, reflexões no sentido de observar como as questôes de reforma educacional geram princípios com o objetivo de ordenar e governar as ações e a participação dos sujeitos envolvidos. Postulam, ainda, que as questôes de reforma sempre apresentam conceitos com duplos sentidos, isto é, processos de inclusão, por exemplo, não podem ser analisados sem levar em conta problemas de exclusão que passam a ser inerentes aos processos de inclusão. As certezas estabelecidas nas reformas não podem ser avaliadas sem olharmos também para as incertezas inerentes a tais processos. É nesse movimento que intervimos com a noção de ambivalência. Uma vez que os deslizamentos de sentidos nas políticas educacionais são inevitáveis, a questão que merece ser posta, então, é como aprender a conviver com essa bifurcação de sentidos, ou com a apresentação de uma realidade até então "inesperada", contingente nesse nível curricular.

Essa é uma questão que pode nos ajudar a refletir sobre as reformas educacionais ocorridas no Brasil, especificamente, no caso do presente trabalho, nas Diretrizes Curriculares Nacionais dos cursos de Letras.

\section{A transferência de deveres e a ambivalência de sentidos}

Cabe detalhar um pouco mais a pesquisa de Lindblad e Popkewitz (2004a) a fim de demonstrar como vemos a ambivalência apresentada nesses estudos. ${ }^{4}$ Observaremos alguns resultados que compreendem processos que ocorrem em pares (inclusão/exclusão; certezas/incertezas; descentralização/ centralização etc.) nos exemplos coletados em diversos países estudados.

Iniciando pela Argentina, Dussel (2004) entende que as noçōes de "responsabilidade" e "autonomia", expressões que figuram em reformas educacionais, abrigam discursos sobre administração que, aparentemente, são novos, mas, na verdade, envolvem temas antigos como obediência a regras, incluindo aqui normas de conduta e respeito aos símbolos da pátria.

\footnotetext{
${ }^{4}$ Salientamos que além de trabalhos pertencentes à coletânea organizada por esses autores, outras pesquisas serão incluídas para o propósito do presente artigo.
} 
Chen (2004) repensa a questão da descentralização nas reformas educacionais em Taiwan, observando como esses movimentos são readequados para contemplar conceitos globais, mas que, paradoxalmente, acabam mostrando a coexistência de conceitos locais, revelando, portanto, noções centralizadoras que mostram a continuidade histórica da cultura chinesa com suas raízes no Confucionismo.

Os próprios organizadores dessa coletânea de estudos contribuem com uma análise (2004b) sobre reformas ocorridas na União Europeia, observando quais são as práticas discursivas que as estruturam nos diferentes contextos educacionais. Os autores argumentam que a descentralização é uma forma de individualização que visa administrar as incertezas. Os processos de descentralização são apresentados como mecanismos elaborados para monitorar, ordenar e gerenciar reformas educacionais. Ao mesmo tempo em que a escola é vista como uma instituição injusta, há a promessa de, por meio dela, ser possível atingir igualdade e justiça na sociedade.

A análise apresentada por Muller (2004) sobre as reformas na África do Sul trata das políticas de fusões institucionais que objetivam reduzir de 35 para 21 o número de instituições de ensino de terceiro grau no país, almejando aprimorar a qualidade e a eficiência do ensino. $O$ pesquisador vê esse processo como decorrência de movimentos de globalização, do qual o Estado busca eximir-se ou diminuir suas responsabilidades de mantenedora das universidades. Assim, com as fusōes e as novas parcerias, as universidades podem contemplar influências de outros nichos do mercado que possam atender, futuramente, suas necessidades.

Outro exemplo que mostra os efeitos da descentralização dos deveres do Estado para a sociedade civil vem da França. Van Zanten (2004) analisa o aumento da autonomia atribuída a diversas instâncias políticas da sociedade (regiōes, departamentos, municipalidades), instâncias importantes na área educacional (reitorias, supervisões acadêmicas), como também mudanças nas relaçôes de poder entre diferentes grupos da sociedade (professores e pais inserem-se nesse segmento). Esse é o aspecto que lhe interessa no estudo, no qual observa que o Estado mantém o poder de formular e legitimar políticas administrativas, no entanto, transfere a responsabilidade dos objetivos e princípios para os indivíduos, os pais, a escola etc. Nesse contexto, a pesquisadora investiga o aumento da representatividade dos pais no sistema educacional francês. Uma de suas conclusōes é a distorção de preceitos de unidade e coerência em virtude da grande interferência dos valores e estilo de vida dos pais de classe média que, historicamente, detêm privilégios 
diferenciados em comparação com famílias de poder aquisitivo inferior. Embora a visão desses pais, oriundos da classe média francesa, não apresente poder de decisão em questões curriculares, pedagógicas ou avaliativas, na verdade, exerce significativa influência sobre aqueles que estão envolvidos nas decisões que abordam essas questôes.

Popkewitz e Lindblad (2000), em outro estudo sobre a União Europeia, analisaram também os sistemas de razão que regem as políticas de inclusão e exclusão na educação. Nesse trabalho, questionando o consenso de que há uma inclusão total possível, os autores circulam por diversos países europeus, analisando como processos ditos inclusivos também podem ser exclusivos. Questōes de raça, gênero, processos migratórios, mercado de trabalho, entre outras, estão presentes nessas análises. Sobre inclusão e exclusão no mercado de trabalho, os autores mostram, por exemplo, alguns dados da Organização para a Cooperação e Desenvolvimento Econômico (OCDE). Um dos resultados discutidos vem de um estudo finlandês que revela processos de exclusão que se iniciam antes mesmo da conclusão da formação profissional. O estudo demonstra que apenas um pequeno grupo de estudantes que recebeu regularmente auxílio financeiro teve acesso a uma escolha vocacional e consequente ingresso na carreira profissional.

Em Popkewitz (1998) encontramos outro exemplo de análise sobre reformas educacionais em sua avaliação sobre o Teach for America (TFA). ${ }^{5}$ Em 1990, esse pesquisador foi convidado para avaliar o TFA, cujas preocupaçōes estavam centradas em determinar os sistemas de razão nas maneiras que a questão do sucesso e do fracasso era formulada. Ou seja, ele não estava interessado em determinar como o sucesso ou o fracasso ocorrem, tampouco identificar formas de sucesso ou fracasso e quais sujeitos podem assim ser classificados. Sua investigação buscou compreender como o discurso acerca da questão da criança urbana e rural foi construído.

O primeiro aspecto que salientamos nessa pesquisa é o fato de o TFA ter sido gerado a partir de uma iniciativa privada, reforçando aspecto que temos evidenciado sobre a questão da iniciativa não pública para apresentar propostas de reforma para problemas sociais. Tal ação, na nossa visão, constitui-se em

\footnotetext{
${ }^{5}$ TFA é apresentado em seu trabalho como um programa alternativo para a formação de professores, cuja graduação ocorrera em outras áreas do saber que não em Educação, tendo como objetivo recrutar e treinar essas pessoas para atuarem em escolas urbanas e rurais nos Estados Unidos, onde houvesse escassez de professores.
} 
exemplo ilustrativo de uma descentralização ou desregulamentação de tarefas (BAUMAN, 2001), ou governance, para Lindblad e Popkewitz (2004b, 2004c). Nessa pesquisa sobre o TFA, o avaliador do programa destaca a presença, nas reformas contemporâneas, de discursos da salvação que "tornam" a criança um indivíduo justo, capaz e competente. Para isso, o estudo voltase para a construção de binarismos levantados nos discursos dos professores participantes do TFA que colocavam, de um lado, as normas de inteligência e competência e, de outro, as crianças a serem "salvas" das escolas onde os professores treinados pelo programa foram alocados. A presença desses binarismos faz surgir, para Popkewitz (1998, p. 41), um "duplo", que é o espaço habitado por algo a ser resgatado. Tomemos o exemplo fornecido por um professor entrevistado que coloca em um polo um aluno "ambicioso". A partir da ausência de um segundo polo, cria-se, discursivamente, um "duplo"; no caso, foi proposto um aluno "indiferente". O que o teórico postula é que essa ausência (segundo polo) reinscreve um elemento que deve ser resgatado. A construção dos "duplos" torna, desse modo, impossível para a criança ser "normal" ou estar na média, pois ela está inscrita em um espaço de oposição. Isso ocorre também com a questão que é central em seu estudo sobre a diferenciação entre criança urbana e criança rural, que funciona como um sistema de inclusão e exclusão. Não apenas por estar ligado a imagens cosmopolitas em um polo, e imagens pastorais, em um outro, mas também por esse discurso sobre educação rural e urbana evocar um espaço social no qual grupos étnicos, raciais e minoritários se apresentam como diferentes e devem ser normalizados.

Atentemos para mais um exemplo norte-americano. Em estudo sobre No child left behind (NCLB), ${ }^{6}$ Cochran-Smith e Lytle (2006) lançam um olhar para a maneira como professores, o ensino e o papel dos professores são representados nesse documento. Por possuir caráter normativo e abrangente e por apresentar uma linguagem que sugere um sentimento de igualdade, segundo os pesquisadores, a NCLB deve ser questionada, pois acreditam que

\footnotetext{
${ }^{6}$ Essa lei federal de 2001 tem como objetivo aprimorar o ensino das escolas norteamericanas a partir dos primeiros anos de escolaridade até o Ensino Médio (High School). NCLB está baseada em quatro princípios norteadores: accountability por resultados, maior possibilidade de escolhas para os pais, maior controle local e flexibilidade e ênfase no fazer funcional baseado em pesquisa científica (U.S. DEPARTMENT OF EDUCATION, 2001).
} 
visões sobre ensino e professores contidas nesse documento apresentam falhas, são lineares e reduzidas.

As críticas quanto à representação dos professores, nesse documento, são no sentido de que grande parte da responsabilidade pelo sucesso dos alunos depende dos professores. Transformar o professor na "solução" para os problemas da educação desvia a atenção de outras questôes prementes, como pobreza e racismo, segundo esses pesquisadores. A grande ênfase no conhecimento conteudístico, além de trazer de volta uma ideia de que o conhecimento é transmitido, faz com que professores se tornem consumidores de produtos, implementadores de programas baseados em pesquisa, usuários de dados estatísticos, transmissores de saber e habilidades e corretores das dificuldades dos alunos determinadas por testes. Enfim, de acordo com os autores desse estudo, a NCLB apresenta o professor como um sujeito que, por não estar devidamente preparado para trabalhar com as "dificuldades" dos alunos, deve buscar (consumir produtos) para melhor detectar, nomear, corrigir, e aumentar os dados estatísticos sobre a escolarização. Dessa forma, ele é representado como o problema e também a solução para a educação, ou para tomarmos reflexão de Derrida (1991), ${ }^{7}$ veneno e remédio ao mesmo tempo.

Alguns aspectos nos chamam a atenção nessa análise. Primeiramente, a questão que temos tentado evidenciar sobre a transmissão da responsabilidade para o indivíduo, tanto para as conquistas como para as derrotas, em que a modernidade líquida faz acreditar. Ou seja, esse estudo sobre a NCLB nos faz entender que a ênfase na preparação profissional, segundo essa Lei, depende exclusivamente do professor. Se ele está enfrentando dificuldades na sua prática pedagógica, é porque desconhece pesquisas que possam auxiliá-lo em sua atuação em sala de aula. Sendo assim, ele deve ser, novamente, "treinado e retreinado", pois, desse modo, ele poderá corrigir as "suas" "falhas" e as da escola.

Outra questão, igualmente próxima de análises anteriores, diz respeito aos conceitos que emergem de diferentes partes do mundo, fruto de uma sociedade cada vez mais globalizada, na qual a informação flui rapidamente.

${ }^{7}$ Derrida explora a oposição entre fala e escrita a partir de um texto do filósofo Platão, intitulado Fedro. Entre outras questôes, comenta sobre a ambiguidade dos sentidos veiculados pela palavra de origem grega phármakon, que pode ser traduzida por remédio, ou droga curativa, mas também veneno. Na obra de Platão, a linguagem escrita está associada à palavra phármakon por apresentar essa característica "nociva" de ambivalência. 
Há, segundo esses pesquisadores, uma lógica mundial sobre a competitividade presente na NCLB que se reflete na educação por meio da busca de melhores resultados, aumento de produtividade, aplicação efetiva de recursos disponíveis e índices estatísticos. Finalmente, a posição paradoxal do professor, vista por esses pesquisadores como problema e solução, ou seja, uma construção binária, na qual ambos os polos se retroalimentam, fazendo continuar uma cadeia interminável de ausência e complemento.

Detenhamo-nos na reforma educacional, proposta no documento: White Paper on Education and Training 8 (COMISSION OF THE EUROPEAN COMMUNITIES, 1995). Nesse documento, publicado pelo ComitêEuropeu, o objetivo estava voltado para a educação, cujos subtítulos envolviam o ensino e a aprendizagem rumo a uma "sociedade da aprendizagem". Alguns temas levantados sobre esse documento, que nos interessam, tratam da construção de um determinado perfil de aprendiz. Paralelamente a um levantamento de valores e princípios que um aprendiz deve possuir, há a construção de um aprendiz não desejado, isto é, o fato de privilegiar determinadas características envolve a exclusão de outras. Vejamos algumas passagens, nas quais o perfil desejado do aprendiz de uma sociedade da aprendizagem é esboçado.

Sobre as novas tecnologias da informação e suas influências no mercado de trabalho, aponta-se o desaparecimento do trabalho repetitivo e rotineiro, pois ele passa a ser visto como um conjunto de "atividades inteligentes" que demandam iniciativa e habilidade de adaptação. Em virtude de movimentos de internacionalização na economia, as preocupaçôes do documento são no sentido de aprimorar a competitividade e a qualidade de vida por meio de uma melhor distribuição de recursos pelo mundo. A respeito de valores culturais e sua transmissão para novas geraçôes, o documento aponta que esse não é apenas papel da escola, mas de todos os cidadãos. Dessa forma, enfatiza a importância da capacitação de jovens para serem questionadores e buscarem constantemente novas respostas - aspecto essencial para que a sociedade europeia seja aberta, multicultural e democrática. Trazemos esses aspectos para

${ }^{8}$ White Papers são documentos elaborados para a Comunidade Europeia com propostas para áreas específicas daquela sociedade.

${ }^{9}$ Nossas afirmações estão baseadas na análise do documento e em anotações de aula do professor Dr. Thomas S. Popkewitz, no curso Reform and change in curriculum and instruction, ministrado no Department of Curriculum and Instruction da University of Wisconsin-Madison, EUA, em 2007. 
a discussão, pois, nos documentos que analisaremos a seguir, temas como os aqui apresentados (novas tecnologias, competências e habilidades) serão igualmente abordados. Observaremos a maneira como tais questões são tangenciadas e, principalmente, os deslizamentos de sentidos.

Da mesma forma, incluímos momentos que destacam o papel do ensino voltado para a inovação. Retomando a abordagem sobre as novas tecnologias da informação, características que são normalmente esquecidas, mas que devem ser valorizadas pelos educadores, conforme aponta esse documento, são: a observação, o uso do senso comum, da curiosidade e o desejo de experimentar. A capacidade de julgar, tomar decisões e escolher é apresentada como qualidade essencial para a compreensão do mundo. Tais qualidades contemplam a seleção de critérios para se fazer escolhas, a recordação de lições do passado e habilidade para avaliar o futuro. Esse aspecto sobre a avaliação do futuro nos interessa pela sugestão de que os educadores devem apresentar o mundo como uma construção inacabada para que se possa cultivar um instinto para o futuro. As características desejadas (inovação, curiosidade, poder de julgamento e decisão) são também fontes propulsoras de capacitação do indivíduo para se autogerir, aspecto ilustrativo daquilo que Bauman (2001) classifica como desregulamentação e a privatização das tarefas e deveres modernizantes.

Evocamos novamente o estudo de Lindblad e Popkewitz (2004a) sobre "políticas itinerantes", quando nos deparamos com termos como flexibilidade - apresentada no documento como uma questão central para o ensino a fim de que se possa atender diversos grupos da sociedade, cujos interesses também são variados. Conforme argumentaremos mais adiante, essas noções sobre inovação, flexibilidade, habilidade para avaliar o futuro são propostas decorrentes de uma nova conjuntura social e que despontam, concomitantemente, em diversas partes do mundo. Sendo assim, os caminhos aqui traçados por nós são no sentido de tornar exequíveis nossas problematizações terminológicas, nos documentos que investigaremos a seguir.

Para finalizar esse painel de estudos internacionais, em outro trabalho vindo da Argentina, Dussel (2005) comenta sobre hibridismo nas questôes curriculares, trazendo pesquisa acerca da genealogia do termo e seus usos na teoria e na história do currículo. Iniciando com o uso, no século XIX, pela botânica e zoologia, essa autora mostra como o teórico pós-colonial Homi K. Bhabha formulou o conceito de híbrido em sua teoria. Após apresentar um histórico do termo, a pesquisadora argentina assume como um dos traços da "'hibridação 
contemporânea' a rapidez com a qual opera para incluir distintos discursos e, portanto, a velocidade com a qual se perdem os marcadores originais do discurso" (p. 71). Traz como exemplo a reforma curricular argentina que foi proposta, inicialmente, a partir da reforma espanhola dos anos 1970, que, por sua vez, apropriou-se de reformas ocorridas nos Estados Unidos. Entendemos que sua afirmação sobre a "perda dos marcadores originais do discurso" é controversa, pois acreditamos no discurso como uma dispersão, não se tratando, portanto, da questão de investigar a origem, ou como a autora afirma, a marca original do discurso. Além disso, como a discussão envolve conceitos de hibridismo, que entendemos como uma transformação, na qual se podem ver características "novas", mas também reflexos do "antigo", supomos que analisar a maneira como ocorrem esses processos de transformação seja mais instigante em termos de pesquisas educacionais. De todo modo, tomamos seu exemplo, por acreditarmos que nos ajuda a mostrar alguns rumos das discussões curriculares na América Latina, como também ilustra esse movimento de "políticas itinerantes", já mencionado anteriormente.

Algumas conclusões desse painel apresentado por nós demonstram que aspectos aparentemente opostos fazem parte de um mesmo processo. Assim, uma prática inclusiva também pode ser exclusiva, como um procedimento de descentralização pode, em última análise, reverter em centralização, como o consenso também pode instaurar conflitos que acabam por mostrar a divisão ao invés da unidade. Acreditamos que esses discursos presentes nas reformas educacionais, especificamente na área curricular, circulam também em discussões no Brasil.

\section{A presença das "políticas itinerantes" no contexto brasileiro}

Lembramos que partimos do pressuposto de que, no ambiente da pósmodernidade no qual vivemos, ocorre também, no nosso país, uma delegação de responsabilidades do Estado para a sociedade civil com a consequente implicação desse movimento na educação, nas reformas educacionais brasileiras, nos processos de formação de professores e mudanças curriculares.

Entendemos que as discussões sobre reformas curriculares no Brasil são também pensadas de uma perspectiva que considera mudanças históricas, culturais, sociais e econômicas ao redor do mundo. Com efeito, Lopes e Macedo (2005) salientaram que algumas palavras de ordem formuladas nacionalmente tais como "hibridismo", "multiculturalismo" e "alteridade" são vistas como decorrências de movimentos de globalização econômica e 
mundialização da cultura. Com o objetivo de aprofundar essa discussão, recorremos às Diretrizes Curriculares Nacionais dos cursos de Letras (CONSELHO NACIONAL DE EDUCAÇÃO / CÂMARA DE EDUCAÇÃO SUPERIOR, 2001) - de ora em diante DCL.

Instituídas no âmbito do Conselho Nacional de Educação (CNE), as DCL constituem-se em um conjunto de orientações norteadoras para a formulação do projeto pedagógico dos referidos cursos. Inserimo-nos nas discussōes acerca de políticas linguísticas tomando essas Diretrizes por percebermos suas marcas de ambivalência, isto é, as orientações apresentadas podem, naturalmente, ser desdobradas, desmembradas, ou apontar para rumos distintos. Argumentamos também que algumas sugestôes apontadas nos documentos são reflexos de um contexto pós-moderno, no qual os conceitos "viajam" e se transmutam e as obrigaçôes tornam-se a cargo do indivíduo.

Conforme já sinalizamos em outro trabalho (COSTA, 2009), as DCL vinculam as reformas educacionais às mudanças ocorridas na sociedade que transformam o mercado de trabalho, assim como o fazem as reformas educacionais e as propostas curriculares, em nível internacional. Passemos a observar os princípios norteadores presentes nas DCL:

Os princípios que norteiam esta proposta de Diretrizes Curriculares são a flexibilidade na organização do curso de Letras e a consciência da diversidade / heterogeneidade do conhecimento do aluno, tanto no que se refere à sua formação anterior, quanto aos interesses e expectativas em relação ao curso e ao futuro exercício da profissão. A flexibilização curricular, para responder às novas demandas sociais e aos princípios expostos, é entendida como a possibilidade de:

- eliminar a rigidez estrutural do curso;

- imprimir ritmo e duração ao curso, nos limites adiante estabelecidos;

- utilizar, de modo mais eficiente, os recursos de formação já existentes nas instituições de ensino superior. (CNE/CES, 2001, p. 15, grifos nossos).

No excerto apresentado, observamos a materialização de palavras de ordem ("flexibilidade", "diversidade", "heterogeneidade") como resultado da disseminação de conceitos que a realidade pós-moderna faz propagar. Assim, estabelecemos um diálogo com trabalhos estrangeiros como o estudo de Maguire (2004), por exemplo, que analisa processos de "modernização" no contexto escolar inglês e suas implicações para os professores. Nos documentos analisados, sugere-se que o professor contemporâneo seja flexível. Compreendemos que, nas 
DCL, a flexibilidade é outorgada aos profissionais envolvidos com a questão curricular, que devem "imprimir ritmo", "utilizar recursos" e "eliminar rigidez", ou seja, ela está presente, é parte inerente, pois dito desse modo, é suposta como existente. É interessante notar como essa característica de flexibilidade apresenta simultaneamente seu duplo (POPKEWITZ, 1998), sua outra face, criando um par que designaremos como flexibilidade/rigidez. Dessa forma, não há como dissociar essas noçōes, pois essa flexibilidade irá, fatalmente, apresentar limites, ou ainda, a flexibilização poderá vir a ser negada ou rejeitada, o que levará ao aparecimento do seu duplo: a rigidez. Notemos ainda como a incisa "de modo mais eficiente" ajuda a criar esse efeito binário. Depreende-se, portanto, que os recursos de formação existentes nas instituições de ensino superior não são ou podem não ser utilizados de modo eficiente, que vise à flexibilização.

Os termos "diversidade" e "heterogeneidade", apontados no trecho exposto, parecem pertinentes para uma discussão que leve em consideração os preceitos de uma educação pós-moderna, quais sejam: a desestabilização das verdades únicas, o descentramento e a reformulação de conceitos e perspectivas etc. (KIZILTAN, BAIN e CANIIZARES, 1993; USHER e EDWARDS, 1994; KINCHELOE, 1997, entre outros). Entretanto, para o propósito de nossa reflexão, é valido acatar contribuições dos estudos linguísticos de Authier-Revuz (2001, 2004), para quem, em todo discurso, há inscriçōes de marcas linguísticas de diversos enunciadores, isto é, dizeres formulados de diferentes pontos de vista. Segundo essa autora, a heterogeneidade é constitutiva do sujeito, do discurso e do dizer. Partindo de tal premissa, cabe questionarmos como o professor desenvolverá práticas que deem conta dessa perspectiva. Para Silva (2003, p. 76), numa perspectiva dos estudos culturais, tanto "a identidade como a diferença têm que ser ativamente produzidas. [...] Somos nós que as fabricamos, no contexto de relações culturais e sociais". Nossa preocupação, portanto, reside no fato de que, se o docente que prepara futuros professores de línguas para o exercício do magistério não estiver alerta sobre a complexidade das questôes que envolvem a diversidade (raça, classe socioeconômica, origem, variações linguísticas etc.) e a heterogeneidade (formaçóes discursivas, perspectivas enunciativas, efeitos de sentido etc.), levando em conta uma perspectiva discursiva, seu trabalho didático-pedagógico poderá voltar-se apenas para maneiras preestabelecidas de buscar e manter homogeneidades em sua sala de aula.

Acreditamos que essa "consciência" (da diversidade/heterogeneidade) almejada pelas DCL requer do docente um maior engajamento para desvendar, em sua prática, formas autoritárias e não críticas de ensinar, camufladas por 
uma atitude criativa e libertadora. Esse engajamento deve traduzir-se em pesquisa, em utilização de recursos semióticos, etnográficos, conforme aponta Kincheloe (1997). Esses são alguns caminhos, pois não há garantias de que isso possa despertar no educador uma percepção mais acurada das particularidades de cada aprendiz.

Como, em alguns trechos das DCL, há sugestão para que se observem também as orientações constantes nas Diretrizes Curriculares Nacionais para a Formação de Professores da Educação Básica (de ora em diante DCF), fazse necessário olharmos para os seus princípios norteadores, nos quais há destaque para a formação docente, objetivando preparar para:

I. o ensino visando à aprendizagem do aluno;

II. o acolhimento e o trato da diversidade;

III. o exercício de atividades de enriquecimento cultural;

IV. o aprimoramento em práticas investigativas;

V. a elaboração e a execução de projetos de desenvolvimento dos conteúdos curriculares;

VI. o uso de tecnologias da informação e da comunicação e de metodologias, estratégias e materiais de apoio inovadores;

VII. o desenvolvimento de hábitos de colaboração e de trabalho em equipe. (CONSELHO NACIONAL DE EDUCAÇÃO / CONSELHO PLENO $-\mathrm{CNE} / \mathrm{CP}, 2002$, p. 1, Art. $2^{\circ}$, grifos nossos).

A forma como as noções mencionadas nesse fragmento (acolhimento, aprimoramento etc.) materializam-se linguisticamente (substantivos precedidos por artigos definidos), produz um efeito de que elas prescindem de maiores explicações, como se fossem unívocas. Com isso, os enunciados desse fragmento colaboram com a criação de um discurso difuso, deixando o professor refém de práticas já cristalizadas, ao não precisar posturas e condutas.

Nesse excerto, observamos também a presença de algumas palavras de ordem ou expressões que traduzimos como ecos das "políticas itinerantes": "diversidade", "práticas investigativas", "tecnologias da informação", "materiais de apoio inovadores", "hábitos de colaboração e de trabalho em equipe". Palavras essas que evocam as propostas elaboradas no documento White Paper on Education and Training, analisado anteriormente. Entendemos que essas expressões no texto das DCF dialogam com as DCL com relação ao termo "flexibilidade", se a tomarmos como significado de ligeireza de movimentos ou ainda "aptidão do espírito para se aplicar a diversas ocupações e estudos" 
(HOUAISS, 2001). Assim, o termo "flexibilidade" contempla todas as outras qualidades sugeridas (capacidade de aceitar diferenças, de ser investigativo, inovador, cooperativo etc.). Enfim, notamos que os conceitos podem "viajar" por várias partes do mundo, conforme sugerem Lindblad e Popkewitz (2004a), como também migrar e se transformar em níveis mais próximos, por exemplo, entre as DCL e as DCF. Não queremos com isso mostrar-nos contrários ou rejeitar noções que se tornam disseminadas. A questão que colocamos é a de investigar a forma pela qual essas noçōes aparecem como fruto de um discurso que pode ser identificado como pós-moderno e, principalmente, como elas se tornam fluidas, mutantes, tendo, assim, seus sentidos desdobrados. Sobre esse aspecto, a interpretação de Demo (1999, p. 25-26), a respeito da LDB no 9394, de 20/12/1996, também alerta educadores em geral. Para ele, apesar de a noção de "flexibilidade" ser apropriada ao contexto educacional, alguns riscos (deslizamentos, diríamos) devem ser observados, pois "a flexibilidade pode ser confundida com o abuso do direito de interpretar", como também "pode ser confundida com certo 'vale-tudo".

À maneira de outros países, que elaboraram suas palavras de ordem nas reformas educacionais (Inglaterra: individualismo competitivo; França: nova solidariedade entre classes sociais; Argentina e Taiwan: desregulamentação e responsabilidade pessoal; Portugal: sociedade do conhecimento e globalização), no Brasil, a palavra que se esboça, de modo predominante, é flexibilidade. Mas como isso acontece no interior de um curso de formação de professores de línguas? Quais as implicações para a formação desses professores, dentro do contexto de redistribuição ou diluição de deveres e responsabilidades para o indivíduo, tendências que entendemos como frutos de uma sociedade pósmoderna, ou, nas palavras de Bauman (2001), líquida ou fluida?

Não vemos nesses documentos propostas definitivas para a elaboração curricular dos cursos de Letras (tampouco é nosso interesse propor alteraçōes). Nossa argumentação toma o texto das Diretrizes Curriculares como exemplar de discurso, apontando para fragmentos discursivos que, por apresentarem noçôes complexas, tornam-se ambivalentes, podendo propiciar a continuidade de um determinado tipo de formação docente. Acreditando na complexidade e relevância dos princípios apresentados, somos da opinião de que toda reforma curricular deve ser amplamente discutida por todos que estão envolvidos no processo educacional, caso contrário, documentos como as DCL passarão apenas a fazer parte do conjunto da legislação vigente sobre os cursos de Letras, sendo referenciados apenas em momentos de criação e (re)avaliação de cursos. 
Mediante as discussōes sobre reformas curriculares expostas, parece-nos, neste ponto, inescapável postular uma questão que surge como emergente e, de nosso ponto de vista, bastante óbvia e pertinente: como contemplar as incertezas no âmbito curricular? Tal enfrentamento desponta como impreterível no ambiente da pós-modernidade, pois é nessa conjuntura que a ambivalência e a ambiguidade mostram-se mais evidentes. Considerando que as propostas curriculares deslizam, revelando outros sentidos, que a formação de professores de línguas deve estar voltada para sua capacitação para buscar "novas respostas", sendo preciso desenvolver um "instinto" para avaliar o futuro, parece-nos imprescindível aprendermos a transitar de um terreno "fixo" para um movediço, sobretudo a nos movimentar nesse espaço de incerteza, de ambivalência da pós-modernidade. Precisamos aprender a incorporar, no plano educacional e nos currículos dos cursos de formação de professores, em especial, professores de línguas, discussóes que os auxiliem a envolverem-se com temas como aqueles apresentados nos documentos aqui analisados, mas, principalmente, a reverem constantemente suas opiniōes, considerando que, na pós-modernidade, a transitoriedade mostra-se sempre presente.

Lembramos a distinção entre "educar" e "treinar" proposta por Widdowson (1990), pertinente para este momento da discussão. De acordo com o autor, o treinamento do professor envolve um processo de preparação para se atingir resultados previamente estabelecidos e conhecidos. Pouca ênfase é dada ao caráter inusitado do ensino, uma vez que o treinamento é pautado pela noção de previsibilidade. Por outro lado, a formação de professores diz respeito ao preparo do professor frente à imprevisibilidade das situaçóes educacionais, ou seja, não se trata da aplicação de técnicas padronizadas e prontas para serem mobilizadas em contextos educacionais. Isso significa que o professor deve ser capacitado para reformular ideias e modificar padrões estabelecidos diante das situaçôes imprevisíveis de ensino.

Desse modo, parece-nos impreterível a incorporação da imprevisibilidade, da dúvida, da contingência nas propostas curriculares, para que professores e futuros docentes possam ensinar, movimentando-se com mais autonomia em terrenos de incertezas. A esse respeito, é ilustrativo o estudo de Morin (2006) sobre o pensamento estratégico para se enfrentar a imprevisibilidade da história humana. Considerando a sociedade do conhecimento, na qual as mudanças apresentam valores ambivalentes, esse pensador francês advoga que a educação deve estar voltada para as incertezas ligadas ao conhecimento. Acreditamos na importância do desenvolvimento de um pensamento estratégico para se conviver 
com as incertezas. Antes, porém, um desafio maior deve ser enfrentado: o desenvolvimento de mecanismos que possibilitem a compreensão de que a ambivalência terá sempre espaço cativo no contexto da pós-modernidade, devendo, portanto, ser incorporada à aprendizagem. Para isso, faz-se necessário que professores (re)considerem a aplicabilidade e a mutabilidade dos conhecimentos a serem ensinados, admitindo que tais conhecimentos podem ser (re)construídos com a incorporação das diversas realidades contextuais e extraescolares dos seus alunos.

\section{Considerações finais}

Vimos que a noção de "políticas itinerantes", elaborada por Lindblad e Popkewitz (2004a) e materializada por meio de conceitos recorrentes em diversos países, presente em reformas educacionais, também pode ser encontrada em documentos brasileiros. Nossa interpretação foi a de que tais políticas são decorrentes de movimentos de descentralização e desregulamentação do Estado, que transferem para o indivíduo atribuições antes vistas como obrigaçōes governamentais (BAUMAN, 2001).

Julgando pelos documentos analisados (DCL e DCF), notamos como a noção de "flexibilidade" se constituiu prioridade na formação. Outros termos ou expressóes recorrentes (palavras de ordem) e que se aproximam de algumas "políticas itinerantes", em nível internacional, são: "diversidade", "práticas investigativas", "tecnologias da informação", "materiais de apoio inovadores" e "colaboração e trabalho em equipe". Conforme já enfatizamos, acreditamos que esses conceitos devem ser cuidadosamente observados na realidade escolar, incluindo aqui, políticas linguísticas, reformas curriculares, projetos pedagógicos e cursos de formação de professores/professores de línguas, com o objetivo de entender como os sujeitos implicados nesses processos atribuem sentidos a essas concepçóes. Por isso, é importante que todo docente envolvido no processo de formação conheça o conteúdo de tais documentos e discuta com os futuros professores os sentidos que podem ser construídos no contexto específico do componente curricular do curso de formação docente pelo qual está responsável, não importando tratar-se de uma disciplina voltada para estudos linguísticos, literários ou pedagógicos. Caso contrário, reiteramos que, de acordo com nossa ótica, em função de uma realidade pós-moderna, na qual os conceitos são fluidos, ambivalentes e temporários, essas palavras de ordem poderão assumir finalidade puramente retórica e burocrática. 


\section{Referências}

AUTHIER-REVUZ, J. Entre a transparência e a opacidade: um estudo enunciativo do sentido. Porto Alegre: EDIPUCRS, 2004. 257p.

AUTHIER-REVUZ, J. Palavras incertas: as não-coincidências do dizer. Campinas: Ed. da UNICAMP, 2001. 200p.

BAUMAN, Z. Modernidade líquida. Rio de Janeiro: Jorge Zahar, 2001. 260p.

BAUMAN, Z. Modernidade e ambivalência. Rio de Janeiro: Jorge Zahar, 1999. $334 \mathrm{p}$.

CHEN, Y. Changing patterns of power: rethinking decentralization in the educational reform in Taiwan. In: LINDBLAD, S.; POPKEWITZ, T. S. (Ed.). Educational restructuring: international perspectives on traveling policies. Greenwich, Connecticut: Information Age Publishing, 2004, p. 43-68.

COCHRAN-SMITH, M.; LYTLE, S. L. Troubling images of teaching in no child left behind. Harvard educational review, Cambridge, v. 76, n. 4, p. 668697, winter 2006.

COMISSION OF THE EUROPEAN COMMUNITIES. White paper on education and training: teaching and learning: towards the learning society. Brussels, 29 nov. 1995. Disponível em: <http://aei.pitt.edu/1132/01/ education_train_wp_COM_95_590.pdf> Acesso em: 17 out. 2007.

CONSELHO NACIONAL DE EDUCAÇÃO / CONSELHO PLENO. Resolução CNE/CP 1, de 18 de fevereiro de 2002. Institui Diretrizes Curriculares Nacionais para a Formação de Professores da Educação Básica, em nível superior, curso de licenciatura, de graduação plena. Diário Oficial da União, Poder Executivo, Brasília, DF, 9 abr. 2002. Seção 1, p. 31. Disponível em: <http:// portal.mec.gov.br/cne/arquivos/pdf/CP012002.pdf>. Acesso em: 10 jan. 2008. CONSELHO NACIONAL DE EDUCAÇÃO / CÂMARA DE EDUCAÇÃO SUPERIOR. Parecer CNE/CES 492/2001. Diretrizes Curriculares Nacionais dos cursos de Filosofia, História, Geografia, Serviço Social, Comunicação Social, Ciências Sociais, Letras, Biblioteconomia, Arquivologia e Museologia. Diário Oficial da Uniāo, Brasília, DF, 9 jul. 2001. Seção 1e, p. 50. Disponível em: <http:/ /portal.mec.gov.br/cne/arquivos/pdf/CES492.pdf> Acesso em: 10 jan. 2008.

COSTA, M. A. M. Reflexões sobre as Diretrizes Curriculares Nacionais para a formação de professores da educação básica. Cadernos do Aplicação, Porto Alegre, v. 22, n. 2, p. 97-129, jul./dez. 2009.

DEMO, P. A nova LDB: ranços e avanços. 8. ed. Campinas: Papirus, 1999. 160 p.

DERRIDA, J. A farmácia de Platão. São Paulo: Iluminuras, 1991. 126p. 
DUSSEL, I. O currículo híbrido: domesticação ou pluralização das diferenças? In: LOPES, A. C.; MACEDO, E. (Org.). Currículo: debates contemporâneos. 2. ed. São Paulo: Cortez, 2005, p. 55-77.

DUSSEL, I. Educational restructuring and the reshaping of school governance in Argentina. In: LINDBLAD, S.; POPKEWITZ, T. S. (Ed.). Educational restructuring: international perspectives on traveling policies. Greenwich, Connecticut: Information Age Publishing, 2004, p. 3-20.

FOUCAULT, M. Governamentalidade. In: MACHADO, R. (Org.). Microfisica do poder. 18. ed. Rio de Janeiro: Graal, 2003, p. 277-293.

HOUAISS, A.; MELLO FRANCO, F. M.; VILLAR, M. S. (Ed.). Dicionário eletrônico Houaiss da língua portuguesa. Versão 1.0. Rio de Janeiro: Objetiva, 2001. CD-ROM.

KINCHELOE, J. L. A formação do professor como compromisso politico: mapeando o pós-moderno. Porto Alegre: Artes Médicas, 1997. 262p.

KIZILTAN, M. Ü.; BAIN, W. J.; CAÑIZARES M., A. Condições pós-modernas: repensando a educação pública. In: SILVA, T. T. (Org.). Teoria educacional crítica em tempos pós-modernos. Porto Alegre: Artes Médicas, 1993, p. 205-232.

LINDBLAD, S.; POPKEWITZ, T. S. (Ed.). Educational restructuring: international perspectives on traveling policies. Greenwich, Connecticut: Information Age Publishing, 2004a. 220p.

LINDBLAD, S.; POPKEWITZ, T. S. (Ed.). Educational restructuring: (re)thinking the problematic of reform. In: LINDBLAD, S.; POPKEWITZ, T. S. (Ed.). Educational restructuring: international perspectives on traveling policies. Greenwich, Connecticut: Information Age Publishing, 2004b, p. vii-xxxi (Introduction).

LINDBLAD, S.; POPKEWITZ, T. S. (Ed.). Education restructuring: governance in the narratives of progress and denials. In: LINDBLAD, S.; POPKEWITZ, T. S. (Ed.). Educational restructuring: international perspectives on traveling policies. Greenwich, Connecticut: Information Age Publishing, 2004c, p. 69-94.

LOPES, A. C.; MACEDO, E. (Org.). Currículo: debates contemporâneos. 2. ed. São Paulo: Cortez, 2005. 237p.

MAGUIRE, M. The modern teacher: a textual analysis of educational restructuration. In: LINDBLAD, S.; POPKEWITZ, T. S. (Ed.). Educational restructuring: international perspectives on traveling policies. Greenwich, Connecticut: Information Age Publishing, 2004, p. 121-141.

MORIN, E. Os sete saberes necessários à educação do futuro. 11. ed. São Paulo: Cortez; Brasília: UNESCO, 2006. 116p. 
MULLER, J. Responsiveness and innovation in higher education restructuring: the South African case. In: LINDBLAD, S.; POPKEWITZ, T. S. (Ed.). Educational restructuring: international perspectives on traveling policies. Greenwich, Connecticut: Information Age Publishing, 2004, p. 143-165.

POPKEWITZ, T. S. Struggling for the soul: the politics of schooling and the construction of the teacher. New York: Teachers College, 1998. 159p.

POPKEWITZ, T. S.; LINDBLAD, S. Educational governance and social inclusion and exclusion: some conceptual difficulties and problematics in policy and research. Discourse: studies in the cultural politics of education, London, v. 21, n. 1, p. 5-44, apr. 2000.

SILVA, T. T. (Org.). Identidade e diferença: a perspectiva dos estudos culturais. 2. ed. Petrópolis: Vozes, 2003. 133p.

U.S. DEPARTMENT OF EDUCATION. No Child Left Behind Act of 2001. Disponível em: <http://answers.ed.gov/cgi-bin/education.cfg/php/enduser/ std_adp.php?p_faqid=4>. Acesso em: 22 set. 2007.

USHER, R.; EDWARDS, R. Postmodernism and education. London: Routledge, 1994. 246p.

VAN ZANTEN, A. Education restructuring in France: middle-class parents and educational policy in metropolitan contexts. In: LINDBLAD, S.; POPKEWITZ, T. S. (Ed.). Educational restructuring: international perspectives on traveling policies. Greenwich, Connecticut: Information Age Publishing, 2004, p. 167-189.

WIDDOWSON, H. G. Aspects of language teaching. Oxford: Oxford University Press, 1990. 213p.

Recebido em 24/07/2013. Aprovado em 24/10/2013. 